\title{
La reprogramación en la obtención de células madre pluripotentes inducidas
}

\section{Reprogramming in obtaining induced pluripotent stem cells}

\author{
Luis Fernando Tume Farfán
}

Universidad Nacional de Piura, Urb. Miraflores s/n, Castilla - Apartado Postal 295, Piura, Perú

DOI: https://doi.org/10.33017/RevECIPeru2013.0002/

\section{Resumen}

Debido a los problemas éticos que se han venido dando por el uso de embriones como fuente de células pluripotentes, se han desarrollado nuevas fuentes para obtener células con las mismas características. En esta revisión se discuten algunos métodos de reprogramación que se han sido empleados por muchos investigadores alrededor del mundo, partiendo por la trasferencia nuclear y posteriormente con el trabajo de Yamanaka quien empezó a usar la introducción de los cuatro factores de transcripción, Oct3 / 4, Sox2, Klf4 y cMyc que origina con éxito la reprogramación de las células somáticas en células madre pluripotentes inducidas (iPSC), que poseen características genómicas y fenotípicas de células madre embrionarias, además se describe algunas desventajas que tienen estos métodos y los riesgos que involucran el uso del factor de transcripción c-Myc. A pesar de que queda mucho por mejorar en este campo, las células iPS muestran un tremendo potencial para la investigación y sus posibles aplicaciones terapéuticas en la medicina regenerativa.

Descriptores: Pluripotenciales, factores de transcripción, inducidas, reprogramación.

\begin{abstract}
Because of the ethical problems that have been taking for the use of embryos as a source of pluripotent cells , we have developed new sources for cells with the same characteristics. In this review we discuss some reprogramming methods that have been employed by many researchers around the world, starting with the nuclear transfer and later with the work of Yamanaka who began using the introduction of four transcription factors , Oct3 / 4 , Sox2 , Klf4 and c- Myc that originates successful reprogramming of somatic cells into induced pluripotent stem cells ( iPSC), which have genomic and phenotypic characteristics of embryonic stem cells , and discusses some drawbacks with these methods and the risks involve the use of the transcription factor $\mathrm{c}$ Myc . Although much room for improvement in this field, iPS cells show a tremendous potential for research and potential therapeutic applications in regenerative medicine.
\end{abstract}

Keywords: Keywords: Pluripotent transcription factors, induced, reprogramming.

\section{Introducción}

Desde hace mucho, los investigadores vieron la posibilidad de uso la célula madre embrionarias como posible aplicación terapéutica, pero la desventaja ha sido los problemas éticos que implica $[10,14]$. Pero Desde que EI Dr. Shinya Yamanaka médico japonés e investigador de Las células madre adultas en 2006 demostró que las células madre tienen propiedades similares a las células madre embrionarias y que podían ser generadas a partir de fibroblastos de ratón $[17,19]$, se han originado nuevas rutas en la investigación con células madre, ya que estas células pluripotentes poseen una capacidad sorprendente de expansión in vitro y se podrían tomar además como 
modelo de enfermedad degenerativas $[16,13,17]$

En años recientes se han visto grandes avances en la programación de las células somáticas diferenciadas hacia un estado de pluripotencia por métodos que no impliquen la transferencia nuclear. Algunos de ellos pueden presentar un primer paso en el camino hacia la terapia celular individual y sin los problemas relacionados a la recolección de los ovocitos no fecundados de mamíferos. A pesar de que la diferenciación de las células implica cambios genéticos y epigenéticos complejos, ahora es posible generar células con muchas de las propiedades de las células madre embrionarias pluripotentes debido a la transducción retroviral de células diferenciadas. Para lograr la reprogramación de células somáticas a células madre con capacidad pluripotentes, se han usado muchos métodos entre ellos ha sido necesario el uso de factores de transcripción como Oct4 [16, 2, 21], Sox2 y Klf4 que son componentes críticos en varios protocolos de reprogramación [4, 14]. Trabajos recientes han subrayado el potencial de esta estrategia mediante la mejora de la eficiencia del proceso y la demostración de que las células iPS pueden contribuir a muchos tejidos diferentes in vivo, incluyendo la línea germinal. Los estudios demuestran el papel crucial de los factores de transcripción y remodelación de la cromatina en la reprogramación nuclear $[18,15]$.

El objetivo de esta revisión es dar conocer algunos puntos importantes en la reprogramación de células somáticas a células pluripotentes y algunos de los inconvenientes que se han venido dando en este campo de investigación.

\section{Las células madres pluripotenciales inducidas}

La mayoría de las células de un organismo multicelular a medida que desarrollan aumentarán inevitablemente los niveles de diferenciación haciéndose estas células más específicas en su diferenciación [10]. Se define por células pluripotentes a las que son capaces de originar todas las células del embrión o el organismo adulto, pero no tienen la capacidad de autoorganizarse para formar un organismo completo [13]. In vivo esta propiedad única se puede encontrar solamente en las células transitorias de los embriones tempranos, incluyendo la masa celular interna de blastocistos [3]. Hasta finales de 2009, las líneas de células iPS se han generado en varias especies animales, como el ratón, humano, mono Rhesus, rata y cerdo [5]. Aunque se pueden generar iPSCs, la eficiencia del proceso sigue siendo baja (típicamente menos del $1 \%$ de fibroblastos transfectados llega a ser iPSCs [16]. Es por eso que actualmente muchos centros de investigación se están diseñando y modificando los protocolos actuales para obtener mejores resultados ya que los cultivos y la diferenciación de estas células son complejos y costosos. Además de esta desventaja dentro del curso de investigación se ha sugerido que las células madre pluripotenciales inducidas retienen una memoria epigenética, "recuerdos" de las células somáticas de donde derivan $[5,8]$, que se manifiesta como la expresión diferencial de genes y capacidad de diferenciación alterada. Estas observaciones pueden influir en los intentos en curso para utilizar iPSCs para modelos de enfermedades y aplicación terapéutica. [8]. Posteriormente Se ha investigado que las células madre pluripotentes inducidas retener "recuerdos" de las células adultas de la que se derivan [7]. Otros estudios indican que estas células pueden ser rechazadas después del trasplante [2].

Se ha propuesto que se puede inducir a pluripotencialidad en células madre de origen fetal debido a que se ha comprobado que presentan algunas características ventajosas en comparación con sus homólogos neonatales y postnatales, en lo que respecta a la cinética de crecimiento, y el potencial de diferenciación, así como la capacidad de reparación de los tejidos in vivo [21].

Una de las desventajas que se ha tenido en la aplicación in vivo de estas células es que los tejidos muchas veces no facilitan la penetración de estas células para su efecto terapéutico, es por eso que se buscan mecanismos moleculares para facilitar la incorporación exitosa [14].

\section{Métodos de reprogramación de células somáticas}

La diferenciación de las células abarca un gran número de cambios epigenéticos que restringen la estructura accesible única del genoma en la etapa pluripotente [1]. Aparecen cambios en el patrón de expresión de factores de transcripción con una rápida regulación de muchos de los factores de forma muy restrictiva expresados en la etapa pluripotente, esto se traduce en que el desarrollo celular genera cambios radicales en la expresión génica. Desde mucho tiempo ha habido intentos por lograr convertir las células somáticas en 
pluripotentes, tales como, la transferencia nuclear [13].

Los fibroblastos de embriones de ratón y fibroblastos de la piel en los seres humanos se han

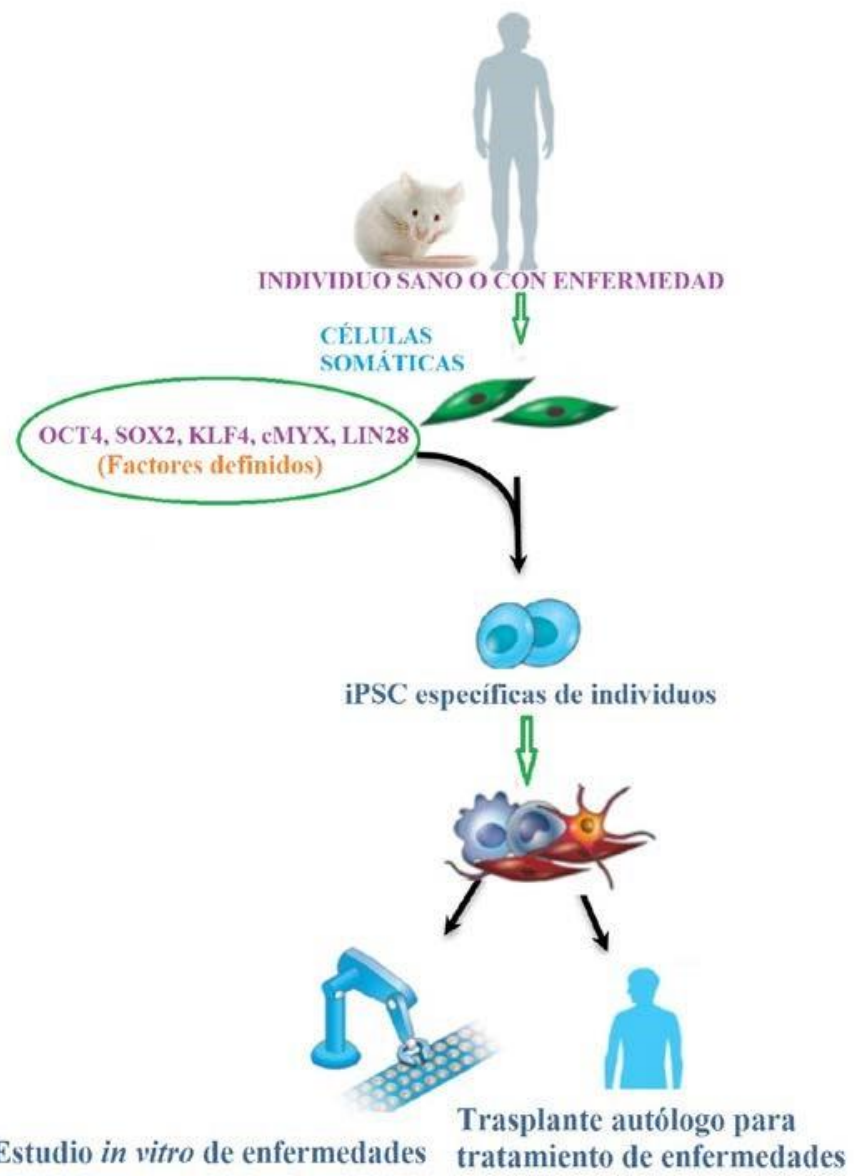

Figura 1. Visión general del proceso de obtención de células madre pluripotentes inducidas con factores de transcripción definidos (Oct4, Sox2, cMyc, Lin28) a partir de células somáticas, para subsecuentemente usarlas para tratamiento de enfermedades o descubrimiento de fármacos.

usado por los investigadores para las reprogramaciones a células iPS. A partir de entonces, otras células, incluyendo las células madre neurales, queratinocitos, melanocitos, células derivadas de tejido adiposo, y diversas células mononucleares de la sangre, se han utilizado con éxito para la reprogramación para lograr una mayor eficiencia, o para mostrar la accesibilidad más fácil y más conveniente. Los estudios iniciales utilizaron integración de ADN de vectores virales tales como retrovirus y lentivirus, pero estudios posteriores demostraron la utilidad de vectores virales nanointegradores tales como, adenovirus, y los sistemas no virales con plásmidos para la reprogramación. Más recientemente, se ha demostrado métodos de entrega que utilizan proteínas recombinantes o proteínas extraídas de células ES para reprogramar células somáticas en células iPS, lo que indica que son clínicamente aplicables para fines terapéuticos [4].
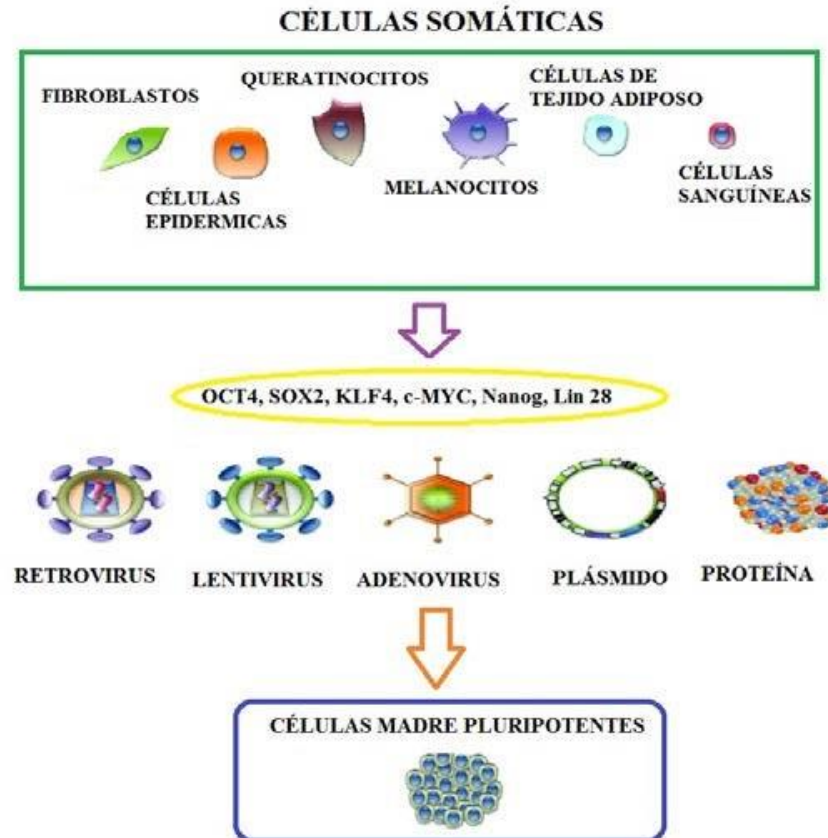

Figura 2. Diferentes fuentes de células somáticas y los métodos de entrega para la generación de células iPS.

\subsection{Fusión celular}

La creación de híbridos de células por fusión de células somáticas con células pluripotentes de diversos orígenes ha mostrado con éxito la exitosa reprogramación de células somáticas de ratones y humanos y como resultado la expresión de marcadores pluripotentes [6,7].

Sin embargo, los híbridos tendrán inevitablemente dos conjuntos de cromosomas, que pueden limitar el uso de este método para las aplicaciones clínicas. La enucleación de células madre embrionarias antes de la fusión puede no ser factible en eludir este problema, ya que se ha demostrado que la abolición de la capacidad del citoplasma de célula madre embrionaria restante vuelve a activar la expresión de marcadores de pluripotencia en híbridos con células somáticas [7]. La eliminación selectiva de los cromosomas es posible, pero puede ser inviable para el conjunto completo [19]. La fusión celular se ha detectado sólo en in vitro hasta ahora y tanto in vitro como in vivo las observaciones han sido tomadas como evidencia de transdiferenciación. 
Una desventaja de este método es que la transdiferenciación se ha reportado en ensayos previos es del $7-57 \%$ con células madre neurales $[11,20]$. Posteriormente se detectó que la fusión celular tiene frecuencias muy bajas como 1 en 104 o 1 en 5 x 105 [32, 38]. Pero cabe destacar que los productos de la fusión celular poseen muchas características de las células madre embrionarias [15].

\subsection{Incubación de células somáticas con extractos de células pluripotentes}

La exposición directa de líneas de células somáticas humanas a los extractos de oocitos de Xenopus [12], células germinales embrionarias [9], células de carcinoma embrionario y células madre embrionarias [3], parecen haber tenido un éxito parcial en la reversión de algunos aspectos de la diferenciación celular, principalmente en la línea de células HEK293T. En la mayoría de los casos se ha registrado re-expresión de marcadores de pluripotencia, especialmente Oct3/4.

\subsection{Utilización de factores de transcripción}

El laboratorio de Yamanaka se centró en factores importantes para el mantenimiento de la pluripotencia en células madre embrionarias, tales como Eras (expresado células madre embrionarias de primates) [3] y se identificaron, en paralelo con el laboratorio de Austin Smith, el gen de pluripotencia Nanog [18, 20.] Yamanaka se embarcó en la búsqueda de inducir pluripotencia en células somáticas. De su trabajo y otros, el conocía un gran número de factores de transcripción que se expresa en las células ES, ya sea con confirmación o sospecha de las funciones en el mantenimiento del estado pluripotente. Además, las células ES se sabe que inducen pluripotencia en los núcleos de células somáticas después de fusiones celulares inducidos entre las células somáticas y ES [13]. Con esta información, Yamanaka seleccionó un conjunto de 24 factores de transcripción de células madre embrionarias que consideró como candidatos para restablecer pluripotencia en células somáticas.

Las células iPS se establecieron por primera vez en 2006 por Takahashi y Yamanaka [9], usando transducción mediada por retrovirus de 4 Factores de transcripción (c-Myc, Oct3 / 4, Sox2 y Klf4) dentro de fibroblastos de ratón [16].
Estas células reprogramadas fueron seleccionadas por la expresión de un cassette ßgeo (una fusión de genes de resistencia a la ßgalactosidasa y neomicina) impulsado por el promotor de ratón Fbx15. Estas células iPS Fbx15, cuando subcutáneamente se inyectan en ratones desnudos, da lugar a teratomas con evidencia histológica de células que se diferencian en las 3 capas germinales. Sin embargo, las células iPS Fbx15 muestran diferente expresión genética, diferentes patrones de metilación del ADN en comparación con las células madre embrionarias y fallan en contribuir a quimeras adultas. Nanog y Oct3 / 4, que están estrechamente involucrados en la pluripotencia, se usan como marcador de selección para las células iPS para obtener células iPS de alta calidad. Esas células iPS seleccionadas por ya sea expresión de Nanog o Oct3 / 4 contribuyen exitosamente a quimeras adultas al mismo tiempo que se muestra la transmisión de la línea germinal [4] y con este método se ha logrado la diferenciación a

hepatocitos primarios in vitro [21]. Dentro del papel importante que tienen estos factores de transcripción cabe destacar que Klf4 interactúa directamente con Oct4 y Sox2 cuando se expresa en niveles suficientes para inducir a células madre pluripotenciales inducidas. Klf4 endógeno también interactúa con Oct4 y Sox2 en las células iPS en células murinas. El C terminal Klf4, que contiene tres dedos de zinc en tándem, es crítico para esta interacción y se requiere para la activación del gen diana Nanog. Además, Klf4 y Oct4 co-ocupan el promotor Nanog. Una mutante dominante negativo de Klf4 puede competir con el de tipo salvaje Klf4 para formar complejos defectuosos Oct4/Sox2/KIf4 e inhibir marcadamente la reprogramación.

El potencial de una reprogramación de fibroblastos murinos primarios en células iPS disminuye a medida que encaminan a la senescencia.

\section{Riesgos de tumorigénesis}

Aunque se pueden generar iPSCs, la eficiencia del proceso sigue siendo baja, típicamente menos del $1 \%$ de fibroblastos transfectados llega a ser iPSCs [36], baja eficiencia en la diferenciación neuronal, además una inclinación para la heterogeneidad fenotípica y la inestabilidad [22]. Por lo tanto un obstáculo para la aplicación clínica de células iPS es el riesgo de tumorigénesis. Muy recientemente, se ha informado de que las células iPS pueden ser generadas sin necesidad de solo c-Myc [15]. Se ha creado un método para generar células iPS 
humanas a partir de células derivadas de la orina libre de virus, sin suero y sin el oncogén c-Myc, donde presentan una alta eficiencia de reprogramación, que ofrece ventajas con respecto a otros tipos de células utilizadas con fines de generación de iPS [10]. Es por eso que el establecimiento de estrategias de reprogramación de proteínas o basada en tipos de ARN ayudará a generar células iPS humanas sin alteraciones genéticas permanentes [5].

\section{Conclusión}

Las células madre pluripotenciales inducidas que actualmente son generadas por la introducción de los factores de transcripción Oct3 / 4, Sox2, Klf4 y c-Myc en fibroblastos y otras células somáticas, poseen muchas características células madre embrionarias. A pesar de los grandes avances que se han realizado en este campo se tiene que tener en cuenta el riesgo de tumorigénesis que implica la introducción del oncogén c-Myc, es por eso que muchos protocolos han sido modificados para excluir este factor. Este y muchas otras desventajas se tendrán que tener en cuenta por los investigadores para la posible aplicación terapéutica en humanos.

\section{Agradecimientos}

Mi más sincero agradecimiento al Blgo.Wilder Arteaga Rodriguez de la Universidad Nacional de Piura, por la lectura crítica de este manuscrito.

\section{Referencias}

[1] R. Alberio, K. Campbell, A. Johnson. Reprogramming somatic cells into stem cells. Reproduction 132 (2006) 709-720.

[2] E. Apostolou. Stem cells: iPS cells under attack. Nature 474 (2011) 165-166.

[3] L. Boyer y A. Mathur. Molecular control of pluripotency. Curr Opin Genet Dev 16 (2006) 455-462.

[4] I. Chambers et al. Functional expression cloning of Nanog, a pluripotency sustaining factor in embryonic stem cells. Cell 113 (2003) 643-655.

[5] K. Cheng et al. Epigenetic memory in induced pluripotent stem cells. Nature 467 (2010) 285290.

[6] C. Cowan, J. Atienza, D. Melton. Nuclear reprogramming of somatic cells after fusion with human embryonic stem cells. Science, 309 (2005)1369-1373.

[7] J. Do y H. Scholer. Nuclei of embryonic stem cells reprogram somatic cells. Stem Cells 22 (2004) 941-949.

[8] E. Dolgin. Flaw in induced-stem-cell model. Nature 470 (2011) 13.

[9] C. Freberg et al. Epigenetic reprogramming of OCT4 and NANOG regulatory regions by embryonal carcinoma cell extract. Mol Biol Cell 18 (2007) 1543-1553.

[10] T. Fujimori et al. Analysis of cell lineage in twoand four-cell mouse embryos.

Development, 130 (2003) 5113-5122.

[11] R. Galli et al. Skeletal myogenic potential of human and mouse neural stem cells. Nature Neurosci 3 (2000) 986-991.

[12] C. Hansis et al. Nuclear reprogramming of human somatic cells by xenopus egg extract requires BRG1. Curr Biol 14 (2004) 14751480.

[13] K. Hochedlinger y R. Jaenisch. Nuclear reprogramming and pluripotency. Nature $\mathbf{4 4 1}$ (2006) 1061-1067.

[14] W. Huang et al. Molecular Strategy to Reduce In Vivo Collagen Barrier Promotes Entry of NCX1 Positive Inducible Pluripotent Stem Cells (iPSC(NCX1+)) into Ischemic (or Injured) Myocardium. PLoS One 8(2013).

[15] E. Geoghegan y L. Byrnes. Mouse induced pluripotent stem cells. Int J Dev Biol. 52 (2008) 1015-22.

[16] Z. Jin et al. Modeling retinal degeneration using patient-specific induced pluripotent stem cells. PLoS One 6 (2011) 170-184.

[17] V. Kashyap et al. Regulation of stem cell pluripotency and differentiation involves a mutual regulatory circuit of the NANOG, OCT4, and SOX2 pluripotency transcription factors with polycomb repressive complexes and stem cell microRNAs. Stem Cells Dev 18 (2009) 1093-1108.

[18] M. Lewitzky y S. Yamanaka. Reprogramación de las células somáticas hacia pluripotencia por factores definidos. Current Opinion in Biotechnology 18 (2007) 467-473.

[19] $\mathrm{H}$. Matsumura et al. Targeted chromosome elimination from ES-somatic hybrid cells. Nat Methods 4 (2007) 23-25.

[20] K. Mitsui et al. The homeoprotein Nanog is required for maintenance of pluripotency in mouse epiblast and ES cells. Cell 113 (2007) 631-642 
[21] $\mathrm{H}$. Niwa. How is pluripotency determined and maintained? Development 134 (2007) 635646.

[22] X. Parsons. Human Stem Cell Derivatives Retain More Open Epigenomic Landscape When Derived from Pluripotent Cells than from Tissues. J Regen Med 1 (2013) 23-33.
[23] J. Polo et al. cell type of origin influences the molecular and functional properties of mouse induced pluripotent stem cells. Nature Biotechnology 28 (2010) 848-855.

E-mail: luisfer2105@hotmail.com 